\title{
OPTIMIZATION OF THE STRUCTURE OF INSULATING COMPOSITE MATERIALS
}

\author{
Zeljko KOS, Valerii VYROVOI, Volodymyr SUKHANOV, Mykhailo ZAVOLOKA, Aleksandr GOKHMAN, Iryna GRYNYOVA
}

\begin{abstract}
The article deals with the interdependent relationship between the properties of a structure and the properties of a material, which sets the task of reducing them, even they are indistinguishable, to a certain integrity. The object of research and analysis in the article is a building structure, which is seen as an open self-organized complex structural system. In the main part, the processes of the formation of structures are considered, as well as the classification of structural elements. The article concludes with structural changes related to the self-support and self-development of the network of active elements, which allow the manifestation of adaptation effects and the design-system to function during the normalized period. The importance of self-organization processes during the development and operation of construction systems allow us to attribute it to a selforganizing system. Thus, the building structure can be represented as an open and complex self-organizing system.
\end{abstract}

Keywords: construction systems; open system; self-organized complex; self-organization processes; structural organization

\section{INTRODUCTION}

Operable in adverse conditions, construction structures leave the safe operation mode by changing the properties of the material from which they are made. The main task is to combine the relationships between the properties of the structure and the properties of the material, down to indistinguishability, into a certain integrity. Identifying ways to solve this problem may be due to the attraction of the ideas and methods of the system approach [1]. The object of the research and analysis is the building structure, which is seen as an open complex of the structural self-organized system.

The rationale for such a representation is based on the following:

- it is an integral object;

- it consists of subsystems, which are in certain relationships and connections with each other;

- construction is strictly focused on the implementation of the target laid down in target functions;

- properties of the construction do not reduce to the properties of its components.

Continuing the justification for the allocation of the structure in the form of a system, we can conclude the following:

- the structure-system, being an element of a system of structural systems, creates an uninterrupted structural series of systems of any complexity;

- the representation of the design-system in the systemsystems and in megasystems allows us to consider the issues of a rational use of material and technical resources, taking into account the environmental requirements, both at the construction stage and in the period of individual structures, structures and urban complexes, from unified technical and economic positions;

- the design-system, being a node of interstructural interactions in the system-structure-systems, determines by its state the safe functioning of the entire system;
- the implemented structure is in the design-system and so are the properties of the material, allowing the material to enter into all structural levels of hierarchical systems.

The representation of the design in the form of a priori system involves its structural design [2]. This gives rise to another interpretation of the history of the change in the parameters of the structure and, consequently, of the properties of the system design.

For a different interpretation, the functioning of system designs should be presented as continuous structural transitions, under which the homeostasis of the system is preserved under the conditions of external and internal factors, under the permissible limits of variation of structural parameters.

The fact of continuous change in indicators and structure parameters allows us to present the structure as a function of motion, which defines a certain range of material properties and determines the functional state of the system design. The intensity of the structural transformation of the material when exposed to an operational load structure depends on the initial qualitative composition and the quantitative relationships of structural elements $[3,4]$. The outcomes of structure parameters are a certain set of structural elements at the time of putting the structure into operation. At this point, the structure of the contraction-system has already passed a certain history of formation and development. The beginning of this history falls on the technological period of obtaining the design - the period of the birth and formation of the system.

The technological period is a relatively short period in comparison with the life of the structures. During this period, efforts of designers, engineers and technologists were realized. Prior to this, the disparate models began to merge into a finished model construction system.

The process period is information-intensive. This is due to the concentration of information on the requirements for a product and the information databases that predecessors accumulated on the technological-technical and economic factors for the rational way of producing a concrete 
construction structure, both in the industrial method and under construction conditions.

The functioning of designs systems is seen as an ongoing process of structural transformation that depends on the prehistory of the structural design, which sets the technologist with the following tasks:

- the selection of the design-system model of the structure based on the options of its interaction with the environment during the maintenance period;

- the determination of the dominant elements of the structure, which should ensure the safe operation of the structure-system under the influence of external and internal factors;

- the design of concrete compositions and the designation of technological modes for obtaining a concrete mixture, taking into account the geometric parameters of the structure in order to create the required set of structural elements by their qualitative composition and quantitative ratio;

- the assignment of the design technology production system with a desired set of physical and mechanical properties.

The elements of the structure are classified in 3 categories according to the speed of their reaction to external and internal effects. The three categories are conservative, metastable and active, as the active structural elements have taken cracks and internal interfaces [5]. Their activity is manifested in the following manners:

- the presence of cracks creates in the surrounding material an uneven distribution of internal deformations and stresses, in which stresses relax near the cracks with the concentration at the mouth along the crack front;

- volumetric deformations caused by internal and external factors appear on the shores of cracks and internal interfaces, which leads to their partial dissipation and redistribution between individual subsystems;

- the specificity of cracks is the ability to spontaneously concentrate the stresses caused by almost any external influences, which leads to a change in their parameters and, consequently, to structural changes in individual subsystems and the entire system design.

Thus, the history of the functioning of the structuresystem is directly connected with the history of the selfdevelopment of the network of active elements of the structure at all levels of structural heterogeneities. By taking for granted the reality of active elements in the design of the system structure, you can get answers to legacy issues:

- why the destruction of the structure takes place when the required quality evidence is provided;

- why with the medium, far from critical, deformations and stresses, localized zones of appearance to the development of cracks appear;

- why cracks grow in the compression zone;

- why cracks as a phenomenon, as a rule, are absent in the calculation schemes;
- why calculations do not take into account the residual (technological, initial, hereditary) deformations;

- why in the analytical methods there are no data on the influence of the material structure on the redistribution and dissipation of the deformation energy;

- how the structure of the structure material is combined;

- how to realize the structure of the product by using the material structure;

- how the structure of the material actually participates in the structural design and operation of the structure.

The process of the formation of structures in their history can be viewed as a kind of scenario for the formation and modification of the properties of CBM (composite building materials). In this case, the scenario itself, as a certain plot scheme, should include a detailed description of the emergence, development and implementation, significant for the system of events. Due to the fact that practically for all CBMs, the organization of the structure begins with interparticle interactions, the task is to manage the mechanisms of directed "guidance" of structure elements that are responsible for the safe operation of the final consumer product.

The structure of CBM is formed as a result of rather complex phenomena associated with the occurrence of diverse chemical, physical and mechanical processes. Any process should be studied in the dynamics of its development, which poses the problems of a reasonable choice of dynamic models that enable the describing of the mechanisms of the formation of dynamic structures with the definition of structural elements, the appearance and development of which determines the functional state of the CBM. Under the elements of the structure in the present context are integral components which implement the objectives that contribute to achieving the specified functions and levels of each structural material as a whole.

The principal difference in the mechanisms of organization of cluster structures of disperse systems (CBM models), depending on the qualitative and quantitative compositions of the particles of the disperse phase, leads to the manifestation of equifinality effects - from different initial states, various qualitative elements of the structure are formed in different ways in the system. In this case, the final act of the three possible scenarios for the organization's structure is the formation in the beginning of a structurally disordered system periodically arranged structural units clusters of various levels of structural inhomogeneities. As a result of such local cooperative interaction in the system, what is spontaneously formed is a fundamentally new structure for the elements of the inter-cluster interface system.

With the advent of new elements of the structure, the history of the dominant influence of interparticle interactions on the ends of the processes of structure formation ends. The period of further structural design by $\mathrm{CM}$ cluster-cluster interactions through intercluster interfaces that require the use of other structural dynamic models. Scenarios for the formation of a microstructure naturally fit into other 
storylines of the formation of structures at other levels of structural heterogeneity. The polystructural organization of $\mathrm{CBM}$ assumes the coexistence and interdependent influence of structural features of fundamentally dissimilar levels of heterogeneity, which must be taken into account when designing and producing materials and products based on mineral binders.

One of the ways to ensure the safe functioning of the system-design in the system-structure system with the negative effect of the operating environment is to maintain interrelated relationships of active elements at all levels of the subsystems. This can be achieved by directing the organizational structure based on the self-organization phenomena in the process during the manufacture of structures. By the time the design begins to work, a certain set of active elements at all levels of structural heterogeneity should be created in the system with similar ones in the material. A specific set of design involves an interconnectivity and interdependence network of active elements based on their interaction and self-support during the period of a system of external and internal loads. Thus, the principle of self-organization of the system during the entire period of its functioning will be realized, which makes it possible to manifest the whole complex of adaptation mechanisms and, therefore, to avoid crisis situations for systems of situations.

In previous works on this topic $[6,7,11]$, the temperature method proposed by us allows us to reliably identify a number of structural inhomogeneities, without resorting to more expensive and time-consuming methods of defectoscopy, such as ultrasound and X-ray. Based on the research conducted in this work, it can be concluded that according to the Wiedemann-Franz law, there will be less heat loss on the surface of the heat-insulating material if the material has both a low thermal conductivity and high specific electrical conductivity. However, this is only possible when using composite materials from an insulator and a conductor.

\section{THE METHODOLOGY OF THE RESEARCH}

Experimental work was carried out on the model of structural cells of concrete, taking into account the interaction of the matrix material with reinforcement (Fig. 1a), porous (Fig. 1b) and dense aggregates (Fig. 1c) with fillers.

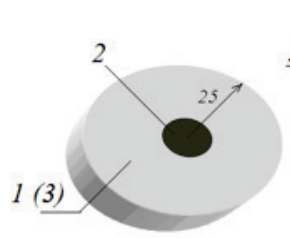

a)

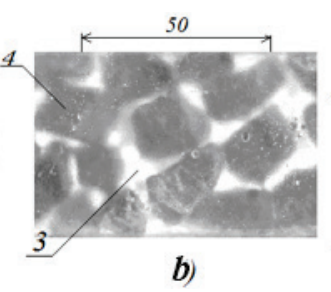

b)

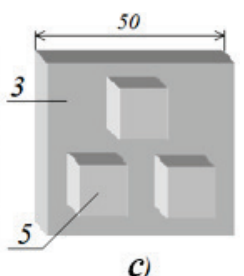

c)
Figure 1 Models of the structural cells of concrete

a) a fragment of reinforcement in the matrix material (concrete), b) coarse aggregate in a cement matrix, c) squareshaped aggregate in the matrix material, 1 - cement stone; 2
- armature; 3 - epoxy resin; 4 - expanded clay gravel; 5 fillers of a square shape.

The matrix material used the cement paste with $\mathrm{W} / \mathrm{C}=$ 0.27 to examine the nature of the cracking of cured matrix material during its interaction with various nature and shape of aggregates. To analyze the influence of the kind of aggregates on the formation of the fields of local and integral deformations, an optically sensitive epoxy resin of the ED20 type with the hardener polyethylene polyamine was used as the matrix.

Condition of development of residual deformations carried graph - analytical method, the method of photoelasticity and speckle - interferometry [7, 8]. A schematic diagram of the interferometer for quantitative and qualitative analysis of deformations in models of structural cells in a three-dimensional measurement is shown in Fig. 2.

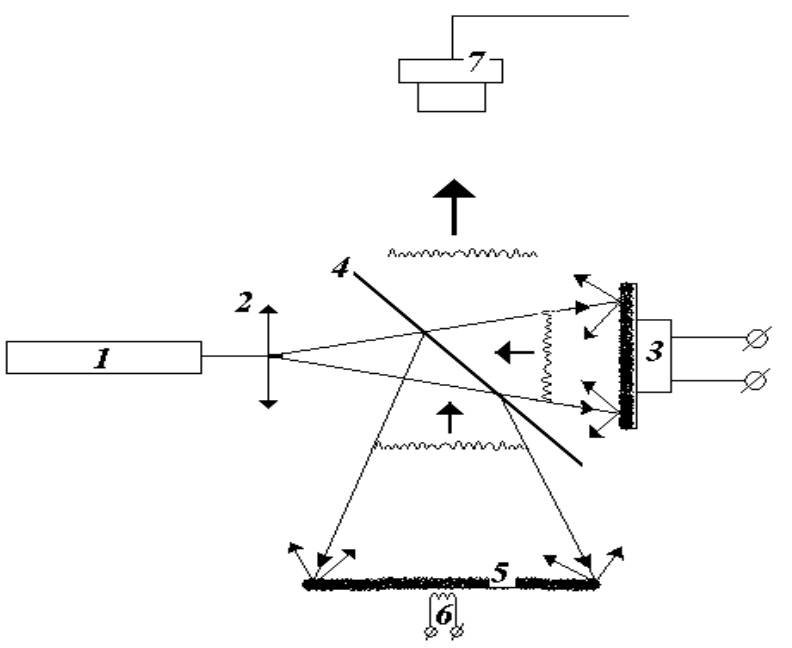

Figure 2 Scheme speckle - interferometer: 1 - helium neon laser, 2 - beam expander, 3 - diffuse diffuser fixed on piezoceramics, 4 - semitransparent mirror, 5 sample, 6 - heater (tungsten helix about $10 \times 5 \mathrm{~mm}$ in size), 7 - camera.

The procedure for carrying out the experiment was as follows: the local temperature was supplied by a $10 \times 5 \mathrm{~mm}$ heater from the bottom in the geometric center of the model of structural cells. At the same time, the change in surface temperature was monitored with an accuracy of $0.5{ }^{\circ} \mathrm{C}$ with an interval of $5 \mathrm{~s}$ and deformations occurring on the surface of the models with an accuracy of $0.03 \mu \mathrm{m}$.

\section{ANALYSIS OF THE EFFECT OF LOCAL HEATING ON THE NATURE OF THE DEVELOPMENT OF DEFORMATIONS}

In the article $[9,10]$ it is told that when local or unilateral change of volume associated with a local or homogeneous change of the humidity and temperature of the samples and products "deformation waves" appear and develop, which are distributed throughout the sample and the product. It was suggested that the material of the article perceiving the energy of the arising deformations transfers it to neighboring parts with a partial distance. As a result, standing waves with variable amplitudes and period are formed, 
which can develop as the volume of local sections changes. A similar pattern of occurrence and development of deformation processes must occur at the level of concrete structural inhomogeneities.

Experimental results showed that the development of deformation processes in the models of structural cells of concrete begins almost simultaneously with the supply of thermal energy. Local and thermal deformations cause the deformation of adjacent volumes of a material and appear on the opposite surface without changing its temperature. A local increase in volume causes the development of deformations of neighboring areas, forming a kind of "deformation wave". The nature of the formation of a deformation wave in a sample of a structurally homogeneous material is shown in Fig. 3

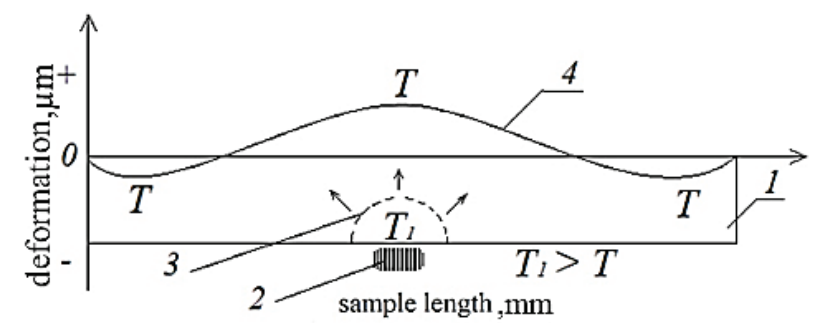

Figure 3 The mechanism of the formation of deformation waves at the local heating of the sample: 1 - sample; 2 - heater; 3 - zone of development of temperature deformations; 4 - change of deformations; $\mathrm{T}$ - initial temperature; T1 temperature change.

In the case of using materials with a certain structural organization, the transfer of deformation energy from one kind of structural inhomogeneities to other will be determined by the state of the interface between the components and their deformation characteristics. This changes the appearance of emerging deformation waves. Fig. 4 shows the mechanism of the formation of deformation waves during the local heating of a sample made of a multicomponent material.

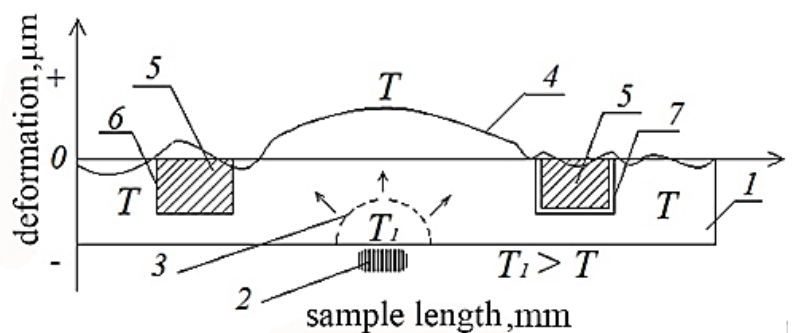

Figure 4 Formation of a deformation wave for the local heating of a sample and a structurally inhomogeneous material: 1 - sample; 2 - heater; 3 - zone of development of temperature deformation; 4 - change of deformations; 5 - structural component with increased deformation characteristics; 6 - perfect adhesion on interphase interfaces; 7 - absence of adhesion forces, bonds on interphase interfaces; $\mathrm{T} 1$ - temperature change.

With perfect adhesion of the matrix material to the surface of the structural inhomogeneity (under the condition $E_{\mathrm{M}}<E_{\mathrm{CH}}$, where is $E_{\mathrm{M}}$ - the modulus of elasticity of the matrix, and $E_{\mathrm{CH}}-$ the modulus of elasticity of the structural component), the deformation energy varies, which affects the nature of the basic deformation wave. In the case of weakened adhesion, the matrix material "sags" on the inclusion, causing half the appearance of local deformations. It can be assumed that similar perturbations of the deformation wave with the local heating of the structurally inhomogeneous material will occur when it meets the shores of the cracks and internal interfaces. The initial local and integral deformations, both at the level of the structural heterogeneities of the material and at the levels of the sample or article, should have a special effect on the character of the development and the type of deformation waves. An example of the emergence and development of the deformation wave is instantaneous volume "portraits" of the deformation state, which arose when local models of structural concrete cells were heated in Figs. 5, 6 and 7.

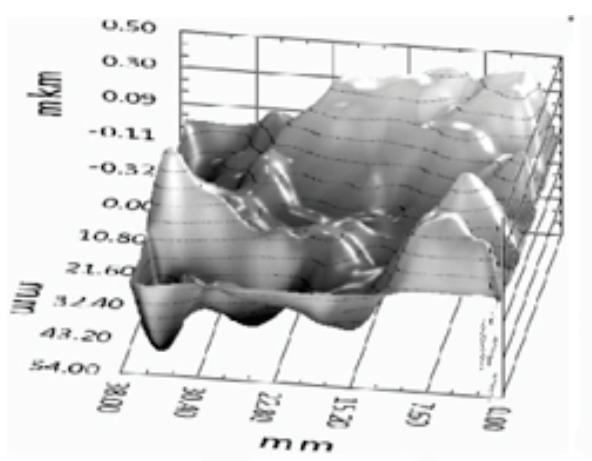

Figure 5 Deformations of the surface of models of structural cells of concrete with fittings

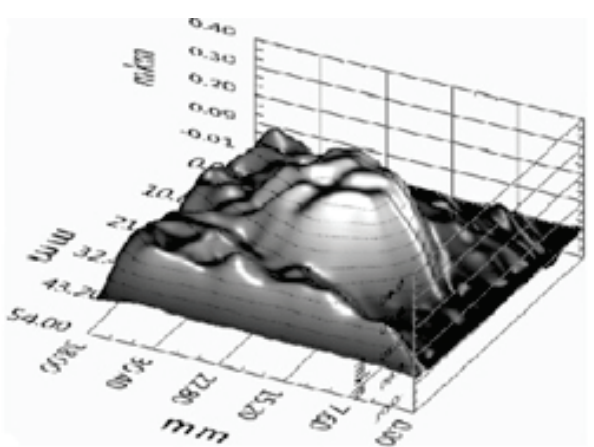

Figure 6 Deformations of the surface of models of structural cells of concrete with expanded clay gravel

The comparison of the deformation state of the model obtained by the speckle-interferometry method after the local temperature supply by the nature of the residual strain distribution obtained by the graphoanalytical method and the photoelasticity method made it possible to determine the effect of residual deformations, the state of the interfaces between the matrix and inclusions, and the type and orientation of the inclusion on the formation deformation waves. This allowed us to recommend this method, after 
improvement, to detect, fix and quantify structural heterogeneities of complexly organized materials.

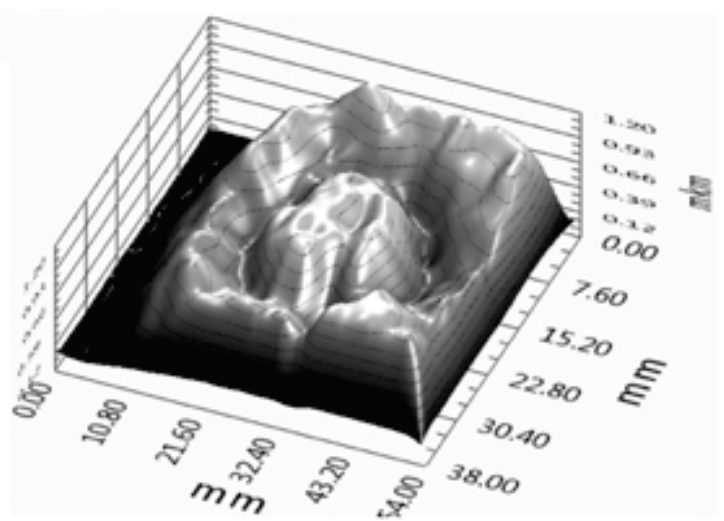

Figure 7 Deformations of the surface of models of structural cells of concrete with a low-modulus filler

The analysis of the kinetics of the formation and propagation of deformation waves made it possible to conclude that the arising deformation perturbations superimposing on the existing non-uniform deformation fields change their general form. In the material there are spontaneously zones, regions, and extent (streams) of material with increased density. It is logical to assume that the transfer of thermal energy will occur through the zones of material with increased density, which will lead to local thermal deformations and, as a consequence, to the formation of deformation microwaves, the latter entering into a component part of the basic deformation waves. In addition to that, the wave process of changing the deformation state should be considered one of the main factors affecting the formation of heat transfer conditions. The coexistence of the zones of different density in the matrix material assumes the formation of heat flows in the form of separate channels or streams, the runoff of which will be determined by the zones of maximum density. Such a stream pattern of heat fluxes will form a kind of percolation cluster in the sample, design and product. Changing the form of percolation clusters due to directed structure formation and "guidance" of residual deformations in the material can be regulated by heat transfer processes in the enclosing structures.

\section{CONCLUSIONS}

The conducted research has shown that when local heat is applied to complex materials, deformation waves arise that pass through the entire sample obtained from these materials. The velocity of propagation of deformation waves is higher than the rate of transfer of thermal energy, which leads to the spontaneous formation of density fluctuations in the material. The formation of density gradients assumes that complex trajectories of heat fluxes are formed in the material, the changing of which makes it possible to change the thermal protective properties of heat-insulating and heat-insulating is a structural materials. Moreover, structural changes related to self-support and self-development of the network of active elements enable the manifestation of adaptation effects, which allows the design-system to function during the normalized period. The importance of the processes of selforganization during the creation and operation of the systemdesign allows it to be attributed to a self-organizing system. Thus, the building structure can be represented as an open and complex self-organizing system. Based on the experiments conducted on the formation of the structure of heterogeneous materials, it is possible to predict and produce composite materials with desired properties. In the future, plans are to study the influence of structural inhomogeneities in the form of an interface (cracks), local media and capillarycompacted porous structure of materials to improve their thermal performance.

\section{REFERENCES}

[1] Prangishvili, I. V. (2000). System approach and system-wide regularities. Moscow, "SYNTHEGA".

[2] Capra, F. (2004). Hidden connections. Moscow, Publishing house "Sofia".

[3] Vyrovoi, V. N., Dorofeev, V. S., \& Sukhanov, V. G. (2010). Composite building materials and structures. Structure, selforganization of a property. Odessa, Publishing house "TPP".

[4] Sukhanov, V. G., Vyrovoi, V. N., \& Korobko, O. A. (2016). Structure of the material in the structure of the structure. Odessa, Polygraph.

[5] Sukhanov, V. G., Vyrovoi, V. N., Cheriega, A. S., Elkin, A. V., \& Dorofeev, A. V. (2011). The role of faults in the destruction of material structures. Modern designs from metal and wood, $15,141-148$.

[6] Vyrovoi, V. N., Zavoloka, M. V., \& Sukhanov, V. G. (2017). Formation of knowledges system in educational process: Scientific and methodological basis for teaching natural sciences and engineering in higher education, 49, 187-193.

[7] Vyrovoi, V. N., Zhukovsky, O. K., \& Gokhman, A. R. (2016). The mechanism of formation of deformation waves under thermal gradient conditions. Bulletin of OSACEA, 62, 61-68.

[8] Nay J. 1991Physical properties of crystals and their description by means of tensors and matrices. Moscow, The World, 1967.

[9] Grigoriev, I. S. \& Meilikhov, E. Z. (1991). Physical quantities. Moscow, Energoatomizdat.

[10] Zavoloka, Yu. M. \& Vyrovoi, V. N. (1997). Features of heat transfer processes in heterogeneous materials. Scientific and Practical Conference. Problems of building thermal physics and energy saving in buildings, 3, 313.

[11] Zhukovsky, V. K., Gokhman, A. R., Zavoloka, Yu. M., \& Vyrovoi, V. N. (2012). Investigation of the stress-strain state of composite building materials by the method of speckleinterferometry. Bulletin of OSACEA, 47, 139-147.

\section{Authors' contacts: \\ Zeljko KOS, PhD \\ University North \\ Jurja Križanića 31b, 42000 Varazdin, Croatia \\ +38598757989, zeljko.kos@unin.hr}

Valerii VYROVOI, Doctor of Technical Science, Professor

Odessa State Academy of Civil Engineering and Architecture

4, Didrikhson str., Odesa, Ukraine

vyrovoy@ukr.net 
Volodymyr SUKHANOV, Doctor of Technical Science, Professor

Odessa State Academy of Civil Engineering and Architecture

4, Didrikhson str., Odesa, Ukraine

ecostroy_odessa@ukr.net

Mykhailo ZAVOLOKA, PhD, Professor

Odessa State Academy of Civil Engineering and Architecture

4, Didrikhson str., Odesa, Ukraine

+380674852564, lab.psk.ogasa@ukr.net

Aleksandr GOKHMAN, Doctor of Physical and Mathematical Sciences, Professor South Ukrainian National Pedagogical University named after K. D. Ushynsky

26, Staroportofrankivska str., Odesa, Ukraine

+380967274242, alexander.gokhman@gmail.com

Iryna GRYNYOVA, postgraduate

Odessa State Academy of Civil Engineering and Architecture

4, Didrikhson str., Odesa, Ukraine

+380939799301, irene.grinyova@gmail.com 